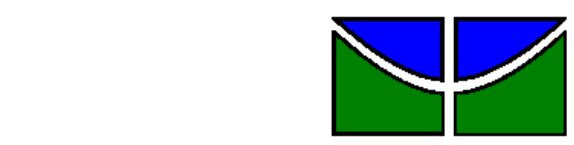

Universidade de Brasília

Faculdade de Economia, Administração e Contabilidade

Departamento de Administração

Curso de Graduação em Administração a distância

MARIA DO CARMO LIMA DE VASCONCELOS

\title{
A RELEVÂNCIA DOS VALORES DO TRABALHO NO COMPROMETIMENTO DO TRABALHOR
}

Brasília - DF 
MARIA DO CARMO LIMA DE VASCONCELOS

\section{A RELEVÂNCIA DOS VALORES DO TRABALHO NO COMPROMETIMENTO DO TRABALHADOR}

Monografia apresentada a Universidade de Brasília (UnB) como requisito parcial para obtenção do grau de Bacharel em Administração.

Professor Supervisor: Dra. Juliana Barreiros Porto Professor Tutor: Msc Alice Damasceno 
Vasconcelos, Maria do Carmo Lima.

A Relevância dos Valores do Trabalho no Comprometimento do Trabalhador / Maria do Carmo Lima de Vasconcelos - Brasília, 2011.

47 f. : il.

Monografia (bacharelado) - Universidade de Brasília, Departamento de Administração - EaD, 2011.

Orientador: Prof. Msc. Alice Damasceno, Departamento de Administração.

1. Valores do Trabalho. 2. Comprometimento Organizacional. 3. Comprometimento Normativo. I. Título 


\section{A RELEVÂNCIA DOS VALORES DO TRABALHO NO COMPROMETIMENTO DO TRABALHADOR}

A Comissão Examinadora, abaixo identificada, aprova o Trabalho de Conclusão do Curso de Administração da Universidade de Brasília do (a) aluno (a)

\section{Maria do Carmo Lima de Vasconcelos}

Msc Alice Damasceno

Professor-Orientador de de 
Ao meu irmão Paulo Juliano, inspiração para tudo o que há de bom em mim. 
Agradeço aos tutores Willier do Nascimento e Alice Damasceno. Ele, pelo apoio durante a disciplina de Metodologia de Pesquisa. Ela, pela qualidade da tutoria. Agradeço, também aos colegas que se dispuseram a participar da pesquisa. 


\section{RESUMO}

O objetivo desta pesquisa foi verificar possíveis relações entre valores relacionados ao trabalho e comprometimento organizacional normativo. Um grupo de 30 funcionários de uma agência bancária do Distrito Federal participou da pesquisa. Foram aplicados os questionários EVT, de Porto e Tamayo (2003) e Modelo de Conceitualização de Três Componentes do Comprometimento Organizacional, validado no Brasil por Medeiros e Enders (1991). A escala de valores do trabalho proposta por Porto e Tamayo (2003) é composta por quatro fatores: Realização, Estabilidade, Relações Sociais e Prestígio. A análise dos questionários demonstrou que os três primeiros fatores foram considerados importantes para o grupo. No entanto, o comprometimento normativo verificado entre os respondentes foi baixo. A pesquisa também revelou que entre os participantes que consideraram Estabilidade, Realização e Relações Sociais como importante, muito importante ou extremamente importante, existiam mais funcionários considerados descomprometidos do que comprometidos.

Palavras-chave: valores do trabalho; comprometimento organizacional; comprometimento normativo. 


\section{LISTA DE TABELAS}

Tabela 1: Motivações do empregado e metas motivacionais ................................20

Tabela 2: Quatro fatores do questionário EVT sugeridos por Porto e Tamayo .........22

Tabela 3: Padrões de definição do trabalho de acordo com o grupo MOW ..............23

Tabela 4: Média e Desvio-padrão para Valores do Trabalho ..................................36

Tabela 5: Relações entre Valores do Trabalho e Comprometimento Normativo.......38 


\section{SUMÁRIO}

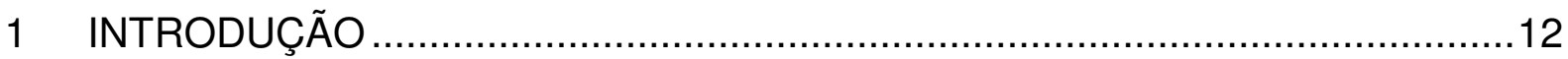

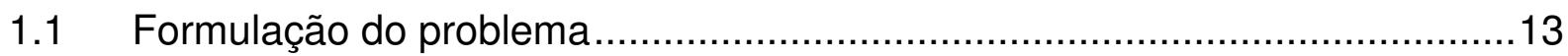

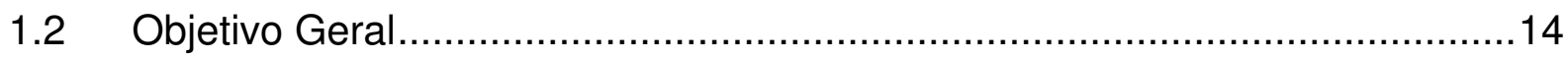

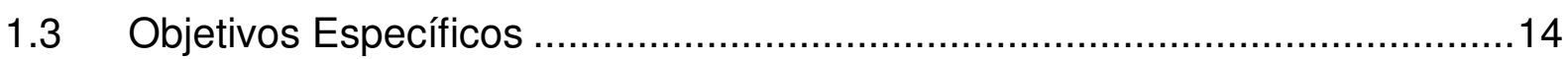

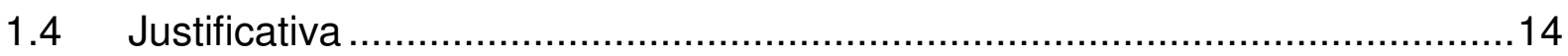

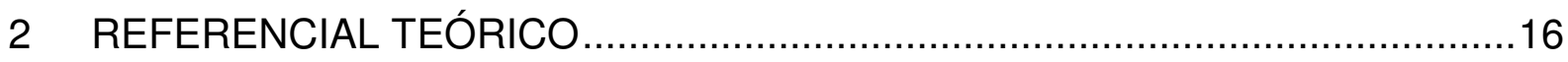

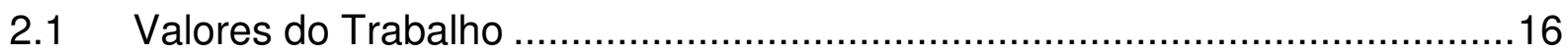

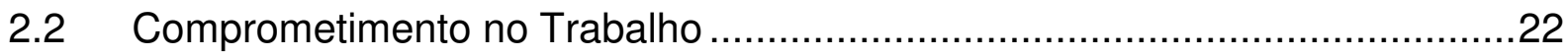

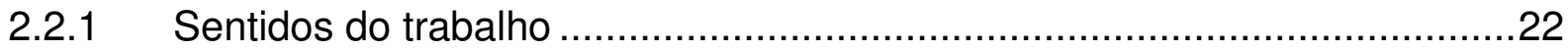

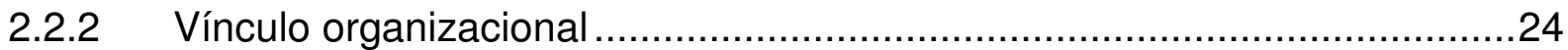

2.2.3 Comprometimento organizacional e comprometimento normativo .............26

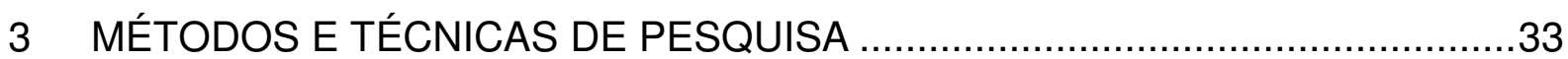

3.1 Tipo e descrição geral da pesquisa .........................................................33

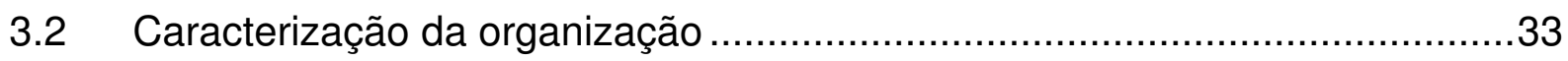

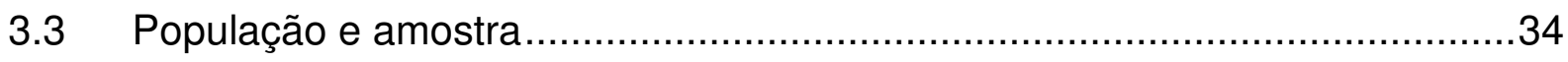

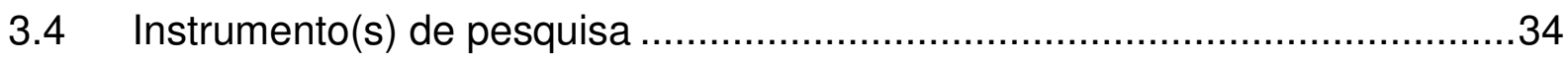

3.5 Procedimentos de coleta e análise de dados .............................................35

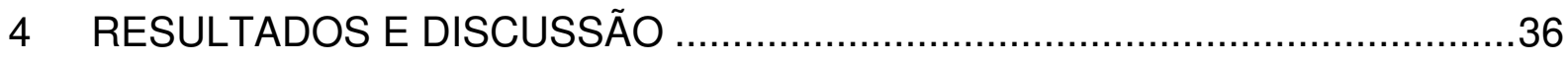

5 CONCLUSÕES E RECOMENDAÇÕES ………........................................

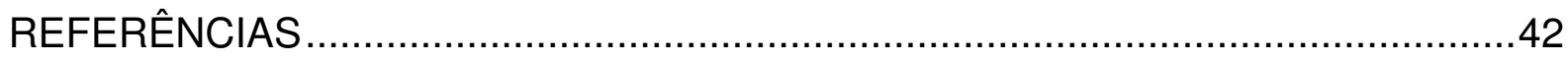

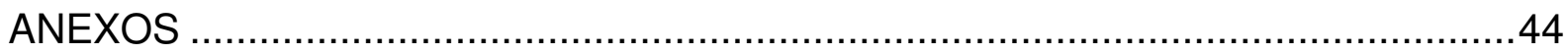

Anexo A - Carta de Apresentação ..........................................................4

Anexo B - Escala de Valores Relativos ao Trabalho.................................46

Anexo C - Modelo de Três Componentes do Comprometimento Origanizacional 


\section{INTRODUÇÃO}

Toda a organização empresarial busca aumento da riqueza de seus proprietários e sobrevivência no mercado. Esta continuidade deve ser sustentada pelo lucro da organização. O uso adequado dos fatores de produção (capital, matérias-primas, mão-de-obra e ferramentas) torna possível o aumento do lucro necessário para manter a viabilidade de qualquer negócio.

Nos princípios da Administração Científica, com Taylor, Ford e Fayol, o foco era crescimento da produção por meio do aumento da produtividade do trabalhador. Os estudos eram baseados na construção de modelos que levassem a fazer mais em menos tempo.

Hoje, entende-se que o comprometimento dos trabalhadores é indispensável para o sucesso das transformações que surgem com as alterações econômicas, tecnológicas e culturais pelas quais vem passando as organizações atuais, conforme apontam Bastos e Borges-Andrade (2002). Desta forma, não podemos pensar em empresas de sucesso que não tenham forte preocupação com seus empregados.

O avanço tecnológico e a própria globalização exigem profissionais capazes de criar e inovar, negociar acordos, tomar decisões, assumir responsabilidades, aprender continuamente, pensar de forma sistêmica, resolver problemas, gerenciar conflitos, dentre outras atividades que exigem habilidades interpessoais, além de amplos conhecimentos e atitude para cumprimento destas "tarefas". Com as mudanças nas exigências do mercado de trabalho, a busca por aumento nos níveis de produtividade não pode ser limitada apenas a estudos de tempos e movimentos.

A satisfação, a motivação do trabalhador, seu bem-estar físico e mental são imprescindíveis para um bom desempenho. Conforme Wagner III e Hollenbeck (1999), a satisfação e a lealdade dos funcionários podem transformar-se em satisfação e lealdade de investidores e clientes. 
O comprometimento com o alcance dos objetivos organizacionais é fator crucial para o bom desempenho no trabalho e o conseqüente aumento da produtividade. $\mathrm{O}$ estudo do comprometimento pode ser uma boa medida para $\mathrm{O}$ comportamento do homem no trabalho; podendo ser relacionado com índices de rotatividade, absenteísmo e qualidade do desempenho (BASTOS, 1993).

Apesar desta importância que o comprometimento tem para o desempenho do trabalhador, sabe-se que nem todas as pessoas ou grupos reagem da mesma forma a determinado estímulo. As representações que cada um tem de todos os aspectos da vida, inclusive os valores relacionados à atividade laboral influenciam o comprometimento do indivíduo com suas atividades (TAMAYO e PASCHOAL, 2003).

\subsection{Formulação do problema}

Nas agências bancárias do Distrito Federal existe grande rotatividade de funcionários. Apesar de 0 interesse desta pesquisa não ser a investigação dos motivos que levam ao desligamento, é importante registrar que há relatos de saída para participação em outras instituições públicas ou privadas; dedicação a estudos em outras áreas ou a cursos preparatórios para ingresso no serviço público; intercâmbio no exterior; acompanhamento de pessoa da família, principalmente cônjuge; não adaptação à cultura e valores da organização.

Neste contexto, surge o questionamento desta pesquisa: Como os valores atribuídos ao trabalho influenciam os bancários do Distrito Federal em seu comprometimento sob o enfoque de padrões internalizados ou noções do que é certo ou moral fazer? 


\subsection{Objetivo Geral}

O objetivo desta pesquisa foi relacionar valores atribuídos ao trabalho por um grupo de funcionários de uma agência bancária do Distrito Federal com o comprometimento em sua perspectiva normativa.

\subsection{Objetivos Específicos}

- Identificar valores atribuídos ao trabalho no grupo pesquisado;

- Mensurar o nível de comprometimento normativo deste grupo;

- Verificar quais os valores estão predominantemente relacionados ao comprometimento normativo.

\subsection{Justificativa}

Verificamos que uma das grandes preocupações das empresas atuais é o comprometimento dos trabalhadores com os objetivos organizacionais. Alguns autores como Bastos (1999) e Tamayo (1998) afirmam que os valores do trabalho têm forte ligação com o comprometimento do trabalhador.

O entendimento da influência das metas e interesses dos trabalhadores pode auxiliar organizações a criar instrumentos motivacionais mais adequados se comparados a instrumentos que desconsiderem estas variáveis, conforme apontam Tamayo e Paschoal, (2003).

Saber quais os fatores e circunstâncias influenciam o comprometimento dos trabalhadores é fundamental, também, na medida em que estes são o principal ativo 
das organizações e seu comprometimento é essencial para a manutenção de relações de qualidade com clientes e investidores.

A definição de Mowday, Steers e Porter (1979, apud MEDEIROS e ENDERS) para comprometimento evidencia a relação entre valores do trabalho e comprometimento organizacional:

Comprometimento é uma relação forte entre um indivíduo identificado e envolvido com uma organização, e pode ser caracterizado por três fatores: estar disposto a exercer um esforço considerável em benefício da organização; a crença e a aceitação dos valores e objetivos da organização e um forte desejo de se manter como membro da organização (pag. 70).

Wiener (1982, apud MEDEIROS e ENDERS) afirma que aceitar os valores e objetivos organizacionais representa uma forma de controle sobre as ações das pessoas. Para autor, pessoas comprometidas adotam certos comportamentos simplesmente por considerá-los certos e morais.

Identificar, dentro de um grupo de trabalho, quais valores estão relacionados a um maior comprometimento organizacional, principalmente em sua perspectiva normativa, pode auxiliar as instituições a identificar quais grupos de funcionários estão mais propensos a se comprometerem com determinadas funções dentro da hierarquia da instituição. 


\section{REFERENCIAL TEÓRICO}

\subsection{Valores do Trabalho}

Para melhor compreensão da relevância dos valores do trabalho no comprometimento do trabalhador é relevante o entendimento do significado de valor e suas variações, valor pessoal e valor organizacional.

Segundo Tamayo (1998, p.57), valor significa a "oposição que o ser humano estabelece entre o principal e o secundário, entre o essencial e o acidental, entre 0 desejável e o indesejável, entre o significante e o insignificante". O autor considera valor como um rompimento da indiferença frente qualquer aspecto da vida (um objeto, um comportamento, um evento, uma idéia, uma pessoa, um lugar), sendo esta manifestação de preferência o comportamento mais comum da vida cotidiana.

Já para Locke (apud TAMAYO e PASCHOAL, 2003, p.41), valores são representações cognitivas de necessidades e motivos. Tamayo e Paschoal (2003) afirmam que os valores representam exigências e demandas culturais, e não somente necessidades individuais.

Valores pessoais se desenvolvem a partir das experiências significativas ocorridas no desenvolvimento social e pessoal do indivíduo. Os valores pessoais representam convicções, idéias ou conceitos que as pessoas aprendem, internalizam e compartilham sobre o que é bom, desejável, certo dentro de uma sociedade ou grupo (SCHWARTZ e ROS, 1995 apud ZANELLI, BORGESANDRADE, BASTOS e cols., 2004, p.166).

De acordo com Oliveira (1995, apud ZANELLI, BORGES-ANDRADE, BASTOS e cols., 2004, p.166), os valores são produtos da reflexão pessoal, ou seja, escolhas pensadas e voluntárias dos seres humanos, passando pelo crivo da 
consciência. Segundo esta abordagem, os valores são filtros para interpretação e manejo da realidade social.

Tamayo (1998) considera valores organizacionais aqueles percebidos como efetivamente característicos da organização pelo seu corpo funcional. De acordo com esta concepção, os princípios e crenças compartilhados pelos empregados é que orientam o funcionamento das organizações.

Estes princípios e crenças são construídos a partir da interpretação dos funcionários de aspectos como a história da organização, sua preferência por comportamentos, padrões de qualidade, estruturas organizacionais, estratégias de gerenciamento, dentre outras escolhas. Tamayo (1998) afirma que os valores são elementos integradores, pois são compartilhados por todos ou pela maioria, servindo como referência e identidade coletiva.

Tamayo (1998) ainda relata três dimensões dos valores organizacionais: cognitiva, motivacional e estruturante. A dimensão cognitiva indica valoração sobre o que é desejável ou não na empresa. Trata-se de respostas prontas e privilegiadas sobre problemas organizacionais repetidos. De acordo com Schwartz e Feather (1994, 1995, apud TAMAYO, 1998, p.58) o aspecto motivacional determina que os valores podem motivar o indivíduo a agir, a seguir determinado caminho e intensidade emocional. Esta dimensão também indica que os valores são metas mais ou menos conscientes da empresa. Já em relação à dimensão estruturante, os valores orientam a vida da empresa e influenciam o comportamento dos funcionários.

Dentre outros aspectos elencados por Tamayo (1998), os valores organizacionais determinam o comprometimento do empregado com o trabalho e com a organização, a identificação com o grupo e a produtividade organizacional, além da satisfação dos empregados com o trabalho e a empresa.

De acordo com Zanelli, Borges-Andrade, Bastos e cols. (2004), valores organizacionais são idéias abstratas sobre o que é bom e desejável para a organização. Eles são construídos a partir de como a organização trata o 
empregado, como a organização estrutura seus processos de trabalho e como a organização se relaciona com o ambiente externo.

Ainda na contextualização dos pesquisadores, a divergência entre valores pessoais e valores organizacionais pode levar à diminuição da motivação para cooperar e se comprometer com as demandas organizacionais. A situação inversa, convergência entre valores pessoais e organizacionais pode contribuir positivamente para o comprometimento no trabalho. Este pensamento está em consonância com Chung e Gibbons (1997, apud TAMAYO, 1998, p.58) ao afirmarem que a interpretação da organização pelos funcionários em divergência com a missão da organização pode levar a "percepções diferentes da empresa, do comportamento organizacional e das tarefas a serem executadas".

Em relação aos valores que as pessoas têm em relação ao trabalho, Schein (1982) afirma que estes variam para cada indivíduo e para o mesmo indivíduo, conforme a idade e a fase evolutiva. $\mathrm{O}$ autor cita os modelos processuais universais de motivação que afirmam que "o comportamento dos trabalhadores depende do grau em que o trabalhador valoriza determinado resultado (...) e do tipo de comportamento que a pessoa espera que possa levar a esse resultado".

Schein (1982) afirma ainda que as profissões que escolhemos, os tipos de organizações nas quais desejamos trabalhar, assim como outros aspectos em nossas vidas, são um processo de elaboração do autoconceito e um movimento em busca da idéia do eu que valorizamos.

Porto e Tamayo (2003) definem valores relativos ao trabalho como:

Princípios ou crenças sobre metas ou recompensas desejáveis, hierarquicamente organizados, que as pessoas buscam por meio do trabalho e que guiam as suas avaliações sobre os resultados e contexto do trabalho, bem como, o seu comportamento no trabalho e a escolha de alternativas de trabalho (2003, p.146). 
É imprescindível a correta diferenciação entre valores pessoais (do indivíduo), valores da organização, presentes na missão, nos objetivos e documentos oficiais e valores organizacionais (valores percebidos pelos empregados como sendo aqueles efetivamente característicos da organização). Zanelli, Borges-Andrade, Bastos e cols. (2004) utilizam a denominação valores declarados para valores da organização e valores arraigados para valores organizacionais.

Quanto à problemática motivacional, Tamayo e Paschoal (2003) afirmam que esta se correlaciona com a interação entre interesses organizacionais e interesses dos funcionários. Para os pesquisadores as estratégias para motivação laboral são mais eficientes quando se relacionam com as metas e valores dos funcionários.

Os autores afirmam que quando a pessoa entra numa empresa, seu interesse básico não é aumentar o lucro da organização, mas sim satisfazer suas necessidades pessoais, suas metas principais da sua existência. A relação onde estas expectativas não são atendidas pode levar o funcionário a se sentir explorado, ao invés de participar de uma relação de troca.

Tamayo e Paschoal (2003) afirmam, ainda, que os esforços para valorização dos funcionários baseados em informações concretas sobre o que eles pretendem atingir na vida e no trabalho são mais eficientes do que estratégias formuladas com base em princípios gerais e abstratos.

Já Schein (1982) afirma que um dos pressupostos para satisfação interna, motivação do trabalhador e produção de alta qualidade, aliada a baixo absenteísmo e rotatividade, é a realização de um trabalho significativo, válido ou importante.

Schwartz (1992, 2001, apud TAMAYO e PASCHOAL, 2003, p.41) elaborou e verificou por meio de pesquisa empírica em mais de 60 países um modelo de estrutura motivacional baseado nas prioridades de valores pessoais.

Conforme esclarecem Tamayo e Paschoal (2003), estrutura motivacional é o conjunto de motivações ou metas que dinamizam o comportamento de cada 
indivíduo e as relações entre essas motivações. Ainda de acordo com os autores, os valores fornecem significado cognitivo e cultural às necessidades, transformando-se em metas e intenções. Neste contexto, valores são como metas motivacionais, sendo alvos a serem atingidos. A tabela 1 indica as dez motivações e respectivas metas específicas.

Tabela 1: Motivações do empregado e metas motivacionais

\begin{tabular}{l|l}
\hline & \multicolumn{1}{c}{ METAS MOTIVACIONAIS } \\
\hline Autodeterminação & $\begin{array}{l}\text { Ter autonomia, decidir por si mesmo e/ou participar nas decisões, controlar } \\
\text { a organização e a execução do seu trabalho. }\end{array}$ \\
\hline Estimulação & $\begin{array}{l}\text { Ter desafios na vida e no trabalho, explorar, inovar, ter emoções fortes na } \\
\text { vida e no trabalho, adquirir conhecimentos novos. }\end{array}$ \\
\hline Hedonismo & $\begin{array}{l}\text { Procurar prazer e evitar a dor e o sofrimento, ter satisfação e bem-estar no } \\
\text { trabalho. }\end{array}$ \\
\hline Realização & $\begin{array}{l}\text { Ter sucesso pessoal, mostrar a sua competência, ser influente, se realizar } \\
\text { como pessoa e como profissional. }\end{array}$ \\
\hline Poder & $\begin{array}{l}\text { Ter prestígio, procurar status social, ter controle e domínio sobre pessoas e } \\
\text { informações. }\end{array}$ \\
\hline Segurança & $\begin{array}{l}\text { Integridade pessoal e das pessoas íntimas, segurança no trabalho, harmonia } \\
\text { e estabilidade da sociedade e organização em que trabalha. }\end{array}$ \\
\hline Conformidade & $\begin{array}{l}\text { Controlar impulsos, tendências e comportamentos nocivos para os outros e } \\
\text { que transgridem normas e expectativas da sociedade e da organização. }\end{array}$ \\
\hline Tradição & $\begin{array}{l}\text { Respeitar e aceitar idéias e costumes tradicionais da sociedade e da } \\
\text { empresa. }\end{array}$ \\
\hline Benevolência & Procurar o bem-estar da família e das pessoas do grupo de referência. \\
\hline Universalismo & $\begin{array}{l}\text { Compreensão, tolerância, procura do bem-estar de todos na sociedade e na } \\
\text { organização onde trabalha, proteção da natureza. }\end{array}$ \\
\hline
\end{tabular}

Fonte: Tamayo e Paschoal (2003), p.42

Os cinco primeiros tipos motivacionais (autodeterminação, estimulação, hedonismo, realização e poder) relacionam-se com alvos da própria pessoa. Os tipos motivacionais tradição, conformidade e benevolência satisfazem interesses ligados à família, à organização e à sociedade. Já os tipos motivacionais universalismo e segurança têm ligação tanto com a pessoa quanto com os outros. Os resultados das pesquisas de Schwartz indicam que estes tipos motivacionais estão presentes praticamente em todos os países (TAMAYO e PASCHOAL, 2003).

Os cinco tipos motivacionais que sintetizam metas e interesses do indivíduo opõem-se aos tipos motivacionais que expressam metas e interesses coletivos. Os tipos motivacionais segurança e universalismo também são opostos entre si. A estrutura motivacional de cada pessoa é volátil e nem sempre harmoniosa, podendo 
levar a conflitos internos de acordo com esta concepção de polaridade entre tipos motivacionais, conforme argumentam Tamayo e Paschoal (2003).

De acordo com Schwartz (1992, apud PORTO E TAMAYO, 2003, p.147), os dez tipos motivacionais identificados são agrupados em duas dimensões bipolares: Autotranscendência versus Autopromoção e Abertura à Mudança versus Conservação.

Autotranscendência agrupa Universalismo e Benevolência, enfatizando a igualdade e a preocupação com o bem-estar dos outros. Em oposição, Autopromoção agrega Poder e Auto-realização, indicando a busca de sucesso e domínio sobre os outros.

Abertura à Mudança agrupa Hedonismo, Estimulação e Autodeterminação e enfatiza a busca de independência de pensamento e ação e o favorecimento à mudança. Por último, Conservação agrega Tradição, Conformismo e Segurança, indicando tradição e proteção da estabilidade e manutenção do status quo.

Porto e Tamayo (2003) são responsáveis por desenvolver e validar uma escala de valores relativos ao trabalho que pode ser aplicada em pessoas da população brasileira com nível de instrução elevada. O desenvolvimento do questionário envolveu procedimentos empíricos e foi embasado em um modelo sólido de valores, a Teoria de Valores de Schwartz.

Para a validação do instrumento, Porto e Tamayo (2003) utilizaram a realização de entrevistas, a aplicação de questionários com perguntas abertas e o levantamento de instrumentos encontrados na literatura.

Grupos diferentes participaram das fases iniciais para validação da EVT. O questionário final foi respondido por 402 empregados com idade média de 28,4 anos, sendo $64 \%$ do sexo feminino e $36 \%$ do sexo masculino. A amostra era composta de $54 \%$ de católicos e $62 \%$ de solteiros. O tempo médio de emprego do grupo pesquisado foi de 9,2 anos. Os entrevistados tinham pelo menos $2^{\circ}$ grau completo e $59 \%$ curso superior incompleto. 
A Tabela 2 apresenta os quatro fatores encontrados por Porto e Tamayo (2003).

Tabela 2: Quatro fatores do questionário EVT sugeridos por Porto e Tamayo

\begin{tabular}{l|l}
\hline DENOMINAÇÃO & \multicolumn{1}{c}{ DESCRIÇÃO } \\
\hline Fator 1 & $\begin{array}{l}\text { Realização no trabalho que se refere à busca de prazer e realização pessoal e } \\
\text { profissional, bem como de independência de pensamento e ação no trabalho por } \\
\text { meio da autonomia intelectual e da criatividade; }\end{array}$ \\
\hline Fator 2 & $\begin{array}{l}\text { Relações sociais que se refere à busca de relações sociais positivas no } \\
\text { trabalho e de contribuição positiva para a sociedade por meio do trabalho; }\end{array}$ \\
\hline Fator 3 & $\begin{array}{l}\text { Prestígio que se refere à busca de autoridade, sucesso profissional e poder de } \\
\text { influência no trabalho; }\end{array}$ \\
\hline Fator 4 & $\begin{array}{l}\text { Estabilidade que se refere à busca de segurança e ordem na vida por meio do } \\
\text { trabalho, possibilitando suprir materialmente as necessidades pessoais. }\end{array}$ \\
\hline
\end{tabular}

Fonte: Porto e Tamayo (2003), p.151

Os resultados alcançados por Porto e Tamayo (2003) indicam a correspondência entre os quatro fatores relativos ao trabalho e os quatro fatores de ordem superior dos valores pessoais da teoria de Schwartz. O Fator Realização está relacionado à Abertura a Mudança. O Fator Relações Sociais tem relação com Autotranscendência. O Fator Prestígio se associa com Autopromoção, enquanto o Fator Estabilidade está ligado ao fator Conservação.

\subsection{Comprometimento no Trabalho}

\subsubsection{Sentidos do trabalho}

Para uma boa compreensão da influência dos valores relacionados ao trabalho no comprometimento organizacional é interessante analisar os sentidos atribuídos ao trabalho, questão que despertou o interesse de muitos estudiosos a partir da segunda metade do século passado.

Em pesquisa realizada no Brasil por Morin, Tonelli e Pliopas (2007), verificou-se que o trabalho é essencial na vida das pessoas, sendo, muitas vezes, 
relacionado à sobrevivência. Os autores indicam a existência de estudos que demonstram que o trabalho ocupa um lugar central na vida das pessoas e das sociedades industrializadas. A pesquisa realizada com alunos de um curso de especialização em Administração na cidade de São Paulo foi baseada nos estudos do MOW (Meaning of Work International Research Team). O MOW tem padrões de definição do trabalho em uma escala de A a F, conforme apresentado na Tabela 3.

\section{Tabela 3: Padrões de definição do trabalho de acordo com o grupo MOW}

\begin{tabular}{l|l}
\hline PADRÃO & DEFINIÇÃO \\
\hline Padrão A & $\begin{array}{l}\text { o trabalho acrescenta valor a qualquer coisa, você deve prestar conta do trabalho, } \\
\text { você recebe dinheiro para fazer isso; }\end{array}$ \\
\hline Padrão B & $\begin{array}{l}\text { ao realizar o trabalho existe um sentimento de vinculação, você recebe dinheiro para } \\
\text { realizar isso, você faz isso para contribuir com a sociedade; }\end{array}$ \\
\hline Padrão C & $\begin{array}{l}\text { outros se beneficiam de seu trabalho, você recebe dinheiro para realizar isso, você } \\
\text { faz o trabalho para contribuir com a sociedade, o trabalho é fisicamente exigente; }\end{array}$ \\
\hline Padrão D & $\begin{array}{l}\text { você recebe dinheiro para realizar o trabalho, faz parte de suas tarefas, alguém Ihe } \\
\text { diz o que fazer, não é agradável; }\end{array}$ \\
\hline Padrão E & $\begin{array}{l}\text { o trabalho é mentalmente e fisicamente exigente, você recebe dinheiro para fazer } \\
\text { isso, mas não é agradável; }\end{array}$ \\
\hline Padrão F & existe horário, você recebe dinheiro para fazer isso, faz parte de suas tarefas. \\
\hline Fonte: Morin, Tonelli e Pliopas, 2007, p. 48.
\end{tabular}

Em pesquisas realizadas por afiliados do grupo MOW em mais de oito países, o salário esteve sempre presente na definição de trabalho. Além disso, a concepção de trabalho apresentou-se positiva para os padrões A, B e C.

Assim como Schein (1982), Morin, Tonelli e Pliopas (2007) citam os trabalhos de Hackman e Oldmam (1976) que indicam três condições para se ter um trabalho com sentido: variabilidade das tarefas, identificação com o trabalho e a possibilidade de realizar algo do começo ao fim. Para ter sentido o trabalho deve ter variedade e ser desafiador; possibilitar aprendizagem contínua; permitir autonomia e decisão; possibilitar reconhecimento e apoio; trazer uma contribuição social e permitir um futuro desejável.

Os autores ainda citam os postulados de E. Jacques (1978) de que um trabalho com sentido deve ocupar o tempo da vida, evitar o vazio e evitar a ansiedade. É importante registrar também que a ausência de sentido às atividades 
humanas pode levar a uma "frustração existencial" conforme entendimento de Frankl (1963, apud MORIN, TONELLI e PLIOPAS, 2007, p.49).

\subsubsection{Vínculo organizacional}

A compreensão da dinâmica entre os valores do trabalho e comprometimento organizacional abrange o conceito de vínculo organizacional.

Kramer e Faria (2007) conceituam vínculo organizacional como a relação que o indivíduo estabelece com a empresa a partir do seu trabalho. Além de outros aspectos, esta vinculação indica o grau de ligação do funcionário com a organização. Este engajamento leva ao comprometimento do funcionário com o desempenho e os resultados. Este processo é caracterizado por identificação, sentimento de pertencimento e participação.

A identificação pressupõe a realização de um projeto em comum. Dentro das organizações isto pode ser traduzido como pessoas trabalhando juntas pelos objetivos organizacionais. Os autores citam admiração; viabilização dos projetos pessoais; sentir-se um representante e sentir-se gratificado e motivado no local de trabalho como aspectos ligados à identificação com a organização.

Entre estes itens, a admiração pela organização e a gratificação com 0 trabalho podem indicar o sentimento de obrigação moral de permanecer vinculado à organização. Kramer e Faria (2007) revelam que conforme o trabalho proporciona gratificação aos trabalhadores estes criam uma relação positiva com a organização.

Ainda segundo os pesquisadores, o sentimento de pertença faz os membros sentirem-se "membros efetivos da organização". Isto pressupõe maior integração com as pessoas, e não somente com a organização. As nuances deste sentimento são orgulho de pertencer; sentir-se um membro; sentir-se responsável pela organização; tempo de organização e reação a críticas.

Sentir-se responsável pela organização, responsabilizando-se pelo desempenho, problemas, objetivos e políticas organizacionais podem indicar 
sentimento de obrigação moral de permanecer na instituição. Esta ligação também pode ser evidenciada com o tempo de empresa. Os entrevistados por Kramer e Faria (2007) afirmam acreditar que o tempo de trabalho fortalece a ligação com a firma, que se torna uma segunda casa e os colegas, uma segunda família.

A participação nas decisões é citada como forma de garantir o desempenho e a produtividade, que geralmente são prejudicados pela rotatividade da mão-deobra e por altos índices de absenteísmo. A participação pode incluir questões sobre o trabalho e questões sobre a organização.

Zanelli, Borges-Andrade, Bastos e cols. (2004) indicam quatro tipos de vínculos indivíduo-organização baseados em processos sociais e cognitivistas: comprometimento organizacional, percepção de suporte organizacional, percepção de reciprocidade organizacional e percepção de justiça.

Comprometimento organizacional é entendido como o vínculo que se estabelece entre um empregado e a organização na qual trabalha. As concepções mais aceitas e investigadas do comprometimento organizacional são a afetiva, a calculativa e a normativa. O comprometimento organizacional é considerado um bom indicador para questões como absenteísmo, rotatividade e desempenho (ZANELLI, BORGES-ANDRADE, BASTOS e cols. 2004).

A percepção de suporte organizacional é definida como "crenças globais acerca do quanto o empregador cuida do bem-estar e valoriza as contribuições de seus empregados" (EISENBERGER, HUNTINGTON, HUTCHISON e SOWA, 1986, apud ZANELLI, BORGES-ANDRADE, BASTOS e cols. 2004, p.310).

Dentre os benefícios em decorrência da percepção de suporte organizacional, apontados por Zanelli, Borges-Andrade, Bastos e cols. (2004), estão menor intenção de sair da empresa, maior desempenho, mais satisfação e envolvimento com o trabalho, além de maior comprometimento organizacional afetivo, calculativo e normativo.

Para Siqueira (2003, apud ZANELLI, BORGES-ANDRADE, BASTOS e cols. 2004, p.312) percepção de reciprocidade organizacional é "um conjunto de crenças 
acerca do estilo retributivo adotado pela organização perante contribuições ofertadas por seus empregados".

Estudos realizados no Brasil na década de 1990 apontaram relação positiva entre percepção de reciprocidade organizacional com comprometimento organizacional calculativo e comprometimento organizacional normativo.

A percepção de justiça engloba a percepção de justiça distributiva e a percepção de justiça de procedimentos. Gomide Jr. (1999, apud ZANELLI, BORGES-ANDRADE, BASTOS e cols. 2004, p.323) define percepção de justiça distributiva como a "crença de que as compensações recebidas pelo empregado são justas quando comparadas com o montante de esforço dispensado na realização de suas contribuições". O mesmo autor define percepção de justiça de procedimentos como a "crença do empregado de que são justos os meios utilizados na determinação do montante de compensações que receberá por sua contribuição".

Segundo Zanelli, Borges-Andrade, Bastos e cols. (2004), a percepção de justiça de distribuição está relacionada com satisfação no trabalho, satisfação com salários, cooperação compulsória, comprometimento organizacional calculativo e comprometimento organizacional normativo. Já a percepção de justiça de procedimentos está relacionada a comprometimento organizacional afetivo, confiança no supervisor, cidadania organizacional e cooperação espontânea.

\subsubsection{Comprometimento organizacional e comprometimento normativo}

Bastos, Brandão e Pinho citam os três conceitos de comprometimento apresentados por Bastos (1994) extraídos da linguagem cotidiana. Estas sentenças apontam algumas dificuldades para o uso científico do construto: 
O primeiro aproxima-se dos conceitos de "compromisso", "com envolvimento": descreve formas de como as pessoas se comportam em relação a determinados alvos; "com comprometimento" seria o oposto de "descompromissadamente" e indicaria o grau de atenção, de esforço e cuidado que a pessoa coloca a realizar algo. Por extensão, comprometimento passou a significar um estado do indivíduo: estado de lealdade a algo, relativamente duradouro, e que pode ser descrito por sentenças que delineiam intenções, sentimentos, desejos. Finalmente, um terceiro uso freqüente refere-se à relação entre conjuntos de condições que conduzem a produtos indesejados: comprometer como prejudicar, impedir. (BASTOS, 1994 apud BASTOS, BRANDÃO e PINHO, 1997, p.99)

Comprometimento tem um caráter disposicional e adverbial (RYLE, 1949, 1979, apud BASTOS, BRANDÇÃO e PINHO, 1997, p.100). O caráter disposicional é verificado por meio da propensão a agir, a se comprometer. $O$ caráter adverbial evidencia a necessidade de caracterizar as ações de acordo com certos padrões que estejam de acordo com a expressão "com comprometimento" (BASTOS, BRANDÃO e PINHO, 1997).

O caráter disposicional é mais aceito pelos pesquisadores do assunto. Bastos, Brandão e Pinho (1997) afirmam que o termo é tomado como um estado, cercado de sentimentos ou reações afetivas positivas em relação a algo ao qual se associam intenções comportamentais específicas. Esta atitude envolve as dimensões afetiva, cognitiva e comportamental.

Tomando o enfoque tradicionalmente aceito de analise do comprometimento como uma atitude, Bastos (2001) afirma que:

comprometimento, associa-se a um conjunto de crenças que geram a identificação com a missão e valores, a uma intensidade de ligação afetiva e a uma disposição de permanecer ou continuar em um determinado curso de ação. (pag. 20)

Enquanto na linguagem cotidiana, o conceito de comprometimento possui conotação positiva e negativa, na linguagem científica permanece apenas a 
perspectiva positiva de "engajamento", adesão, envolvimento, identificação, orgulho, apego (BASTOS, BRANDÃO e PINHO, 1997).

Bastos (2000) cita como alvos do comprometimento do indivíduo, a organização, a profissão, o sindicato, o grupo de colegas, as tarefas executadas, os objetivos ou metas do trabalho. O autor, afirma, ainda que aspectos fora do trabalho podem influenciar esse vínculo, como a família, a religião, o partido político ao qual o indivíduo pertença. É de suma importância a observação de que estes focos podem influenciar o trabalhador de forma harmônica ou conflituosa.

Considerando que o conceito geral de comprometimento envolve também indicadores dos processos que o geram, surge a necessidade de definição e diferenciação de tipos de comprometimento organizacional (BASTOS, BRANDÃO e PINHO, 1997).

Para Zanelli, Borges-Andrade, Bastos e cols. (2004), comprometimento é uma interação social baseada em obrigações ou promessas mais ou menos solenes entre as partes.

Comprometimento organizacional é definido como os vínculos que se estabelecem entre empregado e organização, não havendo concordância entre os pesquisadores do assunto quanto à natureza do vínculo (ZANELLI, BORGESANDRADE, BASTOS e cols., 2004).

Allen e Meyer (1990, apud ZANELLI, BORGES-ANDRADE, BASTOS e cols., 2004, p.315) propõem um modelo de comprometimento organizacional baseado em três perspectivas: afetiva, instrumental e normativa. Segundo este modelo, o desejo (comprometimento afetivo), a necessidade (comprometimento instrumental) e a obrigação moral (comprometimento normativo) são capazes de predizer comportamentos como absenteísmo, rotatividade e desempenho.

Baseado no enfoque afetivo de Mowday, Porter e Steers, Bastos (1993, p.54) conceitua comprometimento como "um estado no qual o indivíduo se identifica com uma organização e seus objetivos e deseja manter-se como membro de modo a facilitar a consecução desses objetivos”. Bastos ressalta que, neste contexto, há 
relação com o envolvimento "moral", que implica a identificação e incorporação dos valores organizacionais pelo trabalhador.

Bastos, Brandão e Pinho (1997) citam as contribuições de diversos autores para construção da dimensão afetiva: lealdade, sentimento de pertencer, desejo de contribuir e dar energia para a organização (MOWDAY e cols., 1982); sentimento de orgulho e desejo de afiliação (O' REILLY e CHATMAN, 1986) e prazer de ser membro (ALLEN e MEYER, 1990).

Bastos (1993, p. 56) apresenta o conceito de comprometimento de acordo com a perspectiva instrumental iniciada por Becker como "um mecanismo psicossocial cujos elementos side-bets ou conseqüências de ações prévias (recompensas e custos) impõem limites ou restringem ações futuras". Neste caso, o trabalhador considera os investimentos feitos, como desenvolvimento de competências, contribuições a fundos de pensões, planos de saúde e outros que oneram a saída da organização.

Bastos, Brandão e Pinho (1997) complementam este conceito, afirmando que o trabalhador se sente recompensado com o que the é oferecido pela organização. Fica entendido que a sua saída implicaria sacrifícios econômicos, sociais ou psicológicos.

Já o enfoque normativo, com contribuições dos trabalhos de Etzioni (1975); Azjen e Fishbein (1980); Weiner (1982) e Weiner e Vardi (1990) nos traz a perspectiva cultural no estudo do comprometimento. Nesta concepção, cultura é definida como valores partilhados que produzem pressões normativas sobre os membros (BASTOS, 1993). Estas pressões se associam à motivação instrumental para influenciar o comportamento dos trabalhadores. De acordo com este enfoque, Bastos (1993, p. 58) conceitua o comprometimento como "o conjunto de pressões normativas internalizadas pelo indivíduo para que se comporte congruentemente com os objetivos e interesses da organização". Pesam para este comportamento, a crença de realizar o que é certo e moral.

Bastos, Brandão e Pinho (1997) afirmam que o comprometimento normativo é uma das principais de todas as medidas de comprometimento. Eles citam as 
contribuições de outros autores para definir o construto: congruência entre valores (O' REILLY, CHATMAN e CALDWELL, 1991); aceitação dos objetivos e valores (MAYER e SCHOORMAN, 1992) e propensão ou inclinação em tornar-se comprometido (ANGLE e LAWSON, 1993).

Em estudo realizado por Bastos, Brandão e Pinho (1997) com servidores de quatro universidades federais brasileiras, os pesquisadores identificaram duas subclasses de indicadores atitudinais na orientação normativa:

- Internalização/identificação e obediência a normas e valores, que abrange conhecer e zelar pelos objetivos e interesses da organização;

- Cumprimento do papel/contrato, que indica o cumprimento das obrigações e deveres, disciplina, respeito à hierarquia, solicitude e cordialidade com o chefe.

Zanelli, Borges-Andrade, Bastos e cols. (2004) conceituam o comprometimento normativo como um estado psicológico baseado em experiências anteriores de socialização no convívio familiar e social e também na socialização organizacional iniciada com a entrada do indivíduo na organização.

De acordo com Wiener e Vardi (1980, 1990, apud ZANELLI, BORGESANDRADE, BASTOS e cols., 2004, p.319), esta obrigação moral influencia o indivíduo a guiar seus atos por valores culturais internalizados, muitas vezes, de forma pouco racional. Esta vinculação pode gerar sentimentos de culpa, incômodo, apreensão e preocupação quando a pessoa pensa ou planeja sair da organização.

Segundo Bastos (1994, apud ZANELLI, BORGES-ANDRADE, BASTOS E cols., 2004, p.320) o comprometimento normativo é percebido por padrões de comportamento que indicam "sacrifício pessoal, persistência e preocupação social".

Na concepção de Siqueira (2002, apud ZANELLI, BORGES-ANDRADE, BASTOS e cols., 2004, p.320) o funcionário pensa ter uma dívida social ou a obrigatoriedade de retribuir um favor. 
A crença de dívida social, esta obrigatoriedade de retribuir um favor é que compõe o vínculo moral com a organização (ZANELLI, BORGES-ANDRADE, BASTOS e cols., 2004). De acordo com os postulados de Allen e Meyer (1996, apud ZANELLI, BORGES-ANDRADE, BASTOS e cols., 2004, p.320) a retribuição à organização, destes favores, é permanecer trabalhando nela.

Zanelli, Borges-Andrade, Bastos e cols. (2004) afirmam que o comprometimento normativo integra a identidade do empregado diante de sua relação de troca social, pois integra também as crenças de seu papel social de devedor para com a organização. Os autores indicam, ainda, a existência de estudos nacionais que relacionam o comportamento normativo com níveis de satisfação com o trabalho e comprometimento organizacional afetivo.

Enquanto isso, Allen e Meyer (apud ZANELLI, BORGES-ANDRADE, BASTOS e cols., 2004, p.320) indicam forte ligação entre obrigação moral com a organização e o desejo de permanecer nela.

Para Bastos (2000), o comprometimento se desenvolve gradualmente e muda ao longo do tempo durante a carreira do trabalhador. O autor afirma, também, que o comprometimento normativo aumenta conforme o estágio na carreira.

Os estudos nacionais e internacionais apontam que indivíduos com maiores idades e responsabilidades familiares geralmente são mais comprometidos com a organização. Este comprometimento é menor em indivíduos com maior escolaridade (BASTOS, 2000).

Medeiros e Enders (1998) foram os responsáveis por validar, no Brasil, o questionário para mensuração do Comprometimento Organizacional baseado em Meyer, Allen e Smith (1993). O instrumento é utilizado pra mensurar as três faces do comprometimento organizacional (afetivo, instrumental e normativo).

A amostra pesquisada para validação do questionário foi composta por 398 empregados e 201 gerentes de 201 empresas no Rio Grande do Norte. Após exclusão de 25 questionários que não estavam integralmente respondidos, a amostra remanescente tinha 373 empregados. 
A análise demográfica indicou que $52 \%$ dos entrevistados eram do sexo masculino; 48,7\% dos entrevistados eram solteiros e $43,8 \%$ casados, $6,7 \%$ separados e $0,8 \%$ viúvos. A idade média dos entrevistados foi de 29,3 anos, sendo o mais novo com 14 e o mais velho com 61 anos.

Quanto à escolaridade, a amostra foi composta por $22,5 \%$ de analfabetos ou pessoas com o primeiro grau incompleto; $8,2 \%$ com o primeiro grau completo; $17,6 \%$ com o segundo grau incompleto; $38,4 \%$ com segundo grau completo; $3,1 \%$ com segundo grau completo e curso técnico; 3,8\% com curso superior incompleto; $5,6 \%$ com curso superior e $0,5 \%$ com pós-graduação.

A variação salarial dos entrevistados foi de 1 a 30 salários mínimos e salário médio de 2,44 salários mínimos. Na amostra analisada, 76,9\% das pessoas exerciam a função de auxiliar; $21,3 \%$ a função de chefe ou supervisor e 1,8\% a função de diretor ou gerente.

Quanto ao tempo de serviço, houve variação de 1 mês a 23 anos e média de 3,96 anos. A experiência profissional dos entrevistados foi de 8,67 anos, variando entre 1 mês e 35 anos.

Para a validação do instrumento os autores utilizaram a Análise Fatorial, que confirmou a estrutura tri-dimensional do comprometimento. Os autores agruparam a amostra em oito padrões distintos de comprometimento organizacional usando Análise de Cluster e combinando componentes de comprometimento. Os padrões identificados são: Comprometido nas três dimensões; Descomprometido nas três dimensões; Afetivo; Normativo; Instrumental; Afetivo-Normativo; Instrumental-Afetivo; Normativo-Instrumental.

Além do instrumento composto por 18 itens, Medeiros e Enders (1998) utilizaram também outros dois questionários. O primeiro continha questões fechadas sobre características gerais e demográficas dos entrevistados. O segundo questionário abordava questões sobre produtividade, comprometimento e centralidade no trabalho dos empregados. Este último questionário foi respondido pelo superior imediato do empregado. 


\section{MÉTODOS E TÉCNICAS DE PESQUISA}

\subsection{Tipo e descrição geral da pesquisa}

Esta pesquisa foi definida como aplicada de caráter descritivo. Conforme conceitua Matias-Pereira (2006), a pesquisa aplicada tem o objetivo de gerar conhecimentos para aplicação prática e são dirigidas a solução de problemas específicos. Ainda, segundo o autor, os estudos descritivos são caracterizados por examinar um fenômeno para descrevê-lo de forma integral ou diferenciá-lo de outro fenômeno.

O objetivo deste trabalho foi investigar a relação entre os valores atribuídos ao trabalho e o comprometimento normativo entre funcionários do ramo bancário.

Quanto à natureza das variáveis, temos uma pesquisa quantitativa, pois o interesse é a mensuração da relação entre duas variáveis (valores do trabalho e comprometimento normativo). Segundo Matias-Pereira (2006) a pesquisa quantitativa pressupõe que tudo pode ser mensurado numericamente, classificando e analisando opiniões e informações por meio de técnicas estatísticas.

Quanto à natureza dos dados, estes são considerados primários, tendo em vista a obtenção por meio de questionários.

\subsection{Caracterização da organização}

A coleta dos dados foi realizada em uma agência de um banco com representatividade em todo território nacional. Os funcionários participantes da pesquisa trabalham atualmente em Brasília (DF). 
Por solicitação da instituição financeira não serão utilizados o nome do banco e o nome da agência na qual os questionários foram aplicados.

\subsection{População e amostra}

A pesquisa foi realizada com funcionários 30 funcionários de uma agência bancária do Distrito Federal. A escolha da unidade foi influenciada pelo grande número de funcionários em comparação com outras agências da mesma região e pela diversidade de cargos dentro da unidade.

\subsection{Instrumento(s) de pesquisa}

Para a avaliação dos valores do trabalho foi utilizada a Escala de Valores Relativos ao Trabalho (EVT) de Porto e Tamayo (2003). O instrumento contém 45 itens e os entrevistados responderam à pergunta: "Quais são os motivos que me levam a trabalhar?" escolhendo uma entre as cinco opções em uma escala do tipo Likert de (1) nada Importante a (5) extremamente Importante.

O comprometimento normativo foi avaliado por meio do Modelo de Conceitualização de Três Componentes do Comprometimento Organizacional de Meyer, Allen e Smith (1991), validado no Brasil por Medeiros e Enders (1998). O questionário original é composto por 18 itens. A escala de respostas utilizada é do tipo Likert com respostas em uma escala de 1 a 5, variando de Discordo Totalmente a Concordo Totalmente. Na validação do instrumento no Brasil, Medeiros e Enders (1998) identificaram quatro indicadores do comprometimento normativo: "Eu não deixaria minha organização agora porque eu tenho uma obrigação moral com as pessoas daqui"; "Eu me sentiria culpado se deixasse minha organização agora"; "Mesmo se fosse vantagem para mim, eu sinto que não seria certo deixar min há organização agora" e "Eu devo muito a minha organização". O comprometimento 
normativo foi mensurado a partir da análise destes indicadores, apesar de aplicado o questionário completo.

\subsection{Procedimentos de coleta e análise de dados}

Os instrumentos foram aplicados individualmente no local de trabalho dos participantes.

A amostra foi constituída por 15 homens e 15 mulheres, sendo que $60 \%$ tinham entre 18 e 30 anos, 53,3\% eram casados e 33,3\% tinham filhos. No grupo, $50 \%$ exerciam a função de gerente ou supervisor; $36,6 \%$ exerciam a função de auxiliar ou assistente e 13,3\% exerciam a função de caixa ou escriturário.

Quanto à escolaridade, 53,3\% dos funcionários possuíam nível superior completo ou incompleto e $40 \%$ possuíam pós-graduação. Entre os participantes, $30 \%$ ganhavam até 6 salários mínimos; 30\% ganhavam entre 6 e 12 salários mínimos e 40\% ganhavam mais de 12 salários mínimos.

Foi utilizada análise estatística para verificar relações entre os fatores da escala de valores do trabalho e o comprometimento normativo no grupo pesquisado. 


\section{RESULTADOS E DISCUSSÃO}

A tabela 4 apresenta o resultado da média e do desvio padrão para os valores relacionados ao trabalho, identificados por meio do instrumento EVT de Porto e Tamayo (2003).

Tabela 4: Média e Desvio-padrão para Valores do Trabalho

\begin{tabular}{l|l|l}
\hline Fator & Média & Desvio-padrão \\
\hline Realização & 3,97 & 0,73 \\
\hline Estabilidade & 4,29 & 0,67 \\
\hline Relações sociais & 3,72 & 0,62 \\
\hline Prestígio & 2,63 & 0,68 \\
\hline
\end{tabular}

A amostra pesquisada considerou o fator Estabilidade como o mais importante. Enquanto que o fator Prestígio foi o de menor importância. Apesar de obter a segunda melhor média $(3,97)$, o fator Realização esteve abaixo do fator Estabilidade $(4,29)$; além de possuir o maior desvio padrão entre os quatro fatores. De acordo com os resultados, os participantes consideram o fator Relações Sociais mais importante que o fator Prestígio. Enquanto o primeiro obteve média 3,72; 0 segundo obteve média 2,63.

Tamayo e Paschoal (2003) afirmam que os esforços para valorização dos funcionários devem ser baseados em informações concretas sobre o que eles pretendem atingir na vida e no trabalho. De acordo com esta concepção, estratégias para valorização dos funcionários que fazem parte deste grupo deveriam envolver aspectos ligados à Estabilidade, Realização e Relações Sociais.

No entanto, Schwartz (1992, apud PORTO E TAMAYO, 2003, p.147), defende que as dimensões nas quais os valores são agrupados deveriam ser opostas entre si. Ou seja, o fator Abertura à Mudança (Realização) seria oposto ao fator Conservação (Estabilidade); assim como o fator Autotranscendência (Relações Sociais) seria oposto ao fator Autopromoção (Prestígio). Sob este enfoque, o apelo 
de possíveis estratégias de valorização para este grupo deveria remeter a Estabilidade e Relações Sociais.

Apesar disso, é importante registrar que foi observada pouca variação entre o escore auferido para o fator Estabilidade $(4,29)$ e o fator Realização $(3,97)$. Esta ausência de maior oposição entre estes fatores pode indicar a existência de conflitos pessoais. Esta afirmação está em conformidade com a assertiva de Tamayo e Paschoal (2003) de que a estrutura motivacional de cada pessoa é volátil e nem sempre harmoniosa, podendo levar a conflitos internos de acordo com a concepção de oposição entre tipos motivacionais.

Utilizando o instrumento Modelo de Conceitualização de Três Componentes do Comprometimento Organizacional de Meyer e Allen (1991), validado no Brasil por Medeiros e Enders (1998), foi auferido um escore de 2,70 para comprometimento normativo para o grupo pesquisado. O valor obtido é considerado baixo, tendo em vista que a escala utilizada vai de 1 a 5; sendo que quanto mais próximo de 1 maior a discordância quanto aos indicadores apresentados.

Os funcionários foram agrupados conforme o comprometimento normativo auferido. Os participantes com comprometimento normativo entre 3,50 e 5,0 foram considerados comprometidos. Os funcionários com escore abaixo de 2,50 foram considerados descomprometidos. Já os empregados que obtiveram escores intermediários foram considerados comprometidos parcialmente.

O grupo que apresentou maior comprometimento normativo foi composto por 8 funcionários que obtiveram escore mínimo de 3,50 e máximo de 4,00. O grupo que obteve comprometimento normativo mediano foi formado por 10 funcionários que apresentaram escore mínimo de 2,50 e máximo de 3,25. O grupo que apresentou menor comprometimento normativo tinha 12 funcionários que alcançaram escores entre 1,75 e 1,25.

Estes dados indicam que somente $26,67 \%$ dos participantes foram considerados comprometidos, sob a perspectiva normativa. É importante retomar o conceito de Bastos (1993, p.58) para comprometimento normativo: "conjunto de pressões normativas internalizadas pelo indivíduo para que se comporte 
congruentemente com os objetivos e interesses da organização" e a afirmativa de que pesam para este comportamento, a crença de realizar o que é certo e moral. Pode-se afirmar que a maior parte dos funcionários não está inclinada a contribuir com os objetivos e interesses da organização.

A Tabela 5 apresenta a relação entre funcionários considerados comprometidos, comprometidos parcialmente ou descomprometidos e os escores obtidos para os valores relativos ao trabalho apresentados pelos respondentes.

Tabela 5: Relações entre Valores do Trabalho e Comprometimento Normativo

\begin{tabular}{|c|c|c|c|c|}
\hline \multirow[b]{2}{*}{ Fator } & \multicolumn{3}{|c|}{ Comprometimento Normativo } & \multirow[b]{2}{*}{$\begin{array}{l}\text { Desvio- } \\
\text { padrão }\end{array}$} \\
\hline & Comprometidos & $\begin{array}{l}\text { Comprometidos } \\
\text { parcialmente }\end{array}$ & Descomprometidos & \\
\hline Realização & 4,30 & 3,96 & 3,51 & 0,40 \\
\hline Estabilidade & 4,38 & 4,31 & 4.07 & 0,16 \\
\hline Relações Sociais & 3,94 & 3,78 & 3,24 & 0,37 \\
\hline Prestígio & 2,83 & 2,72 & 2,11 & 0,39 \\
\hline
\end{tabular}

Nos três grupos, o fator Estabilidade foi considerado mais importante que o fator Realização, assim como o fator Relações Sociais foi considerando mais importante que o fato Prestígio. Os fatores Estabilidade e Relações Sociais também foram os que obtiveram o menor desvio padrão $(0,16$ e 0,37 ; respectivamente) demonstrando a pouca variação entre as notas atribuídas pelos participantes para estes fatores.

No grupo que considerou o fator Realização como importante, muito importante ou extremamente importante, $28,57 \%$ foram considerados comprometidos e 39,29\% descomprometidos. Esta proporção foi de 27,59\% de comprometidos e $37,93 \%$ de descomprometidos para o fator Estabilidade. Entre os participantes que consideraram o fator Relações Sociais como importante, muito importante ou extremamente importante, 29,63\% foram considerados comprometidos e 37,93\% descomprometidos. Para o fator Prestígio, esta relação foi de $22,22 \%$ de comprometidos e $22,22 \%$ de descomprometidos.

Estes dados mostram que os fatores Realização, Relações Sociais e Estabilidade apresentaram mais funcionários descomprometidos do que 
comprometidos entre aqueles que consideram cada fator como importante, muito importante ou extremamente importante. Estas informações podem indicar divergência entre os valores relativos ao trabalho na percepção dos funcionários e os valores declarados pela organização. Esta hipótese está em consonância com Zanelli, Borges-Andrade, Bastos e cols. (2004) ao afirmarem que a divergência entre valores pessoais e valores organizacionais pode levar à diminuição da motivação para cooperar e se comprometer com as demandas organizacionais.

Este entendimento pode ser reforçado através da revisão das contribuições de diversos autores para a definição do construto comprometimento normativo realizada por Bastos, Brandão e Pinho (1997): congruência entre valores (O' REILLY, CHATMAN e CALDWELL, 1991); aceitação dos objetivos e valores (MAYER e SCHOORMAN, 1992) e propensão ou inclinação em tornar-se comprometido (ANGLE e LAWSON, 1993). Bastos, Brandão e Pinho (1997) ainda remetem a internalização, identificação e obediência a normas e valores, abrangendo conhecer e zelar pelos objetivos e interesses da organização como um dos indicadores atitudinais da orientação normativa. 


\section{CONCLUSÕES E RECOMENDAÇÕES}

Por meio da análise dos questionários validados para mensurar os valores relativos ao trabalho e o comprometimento normativo foi possível estabelecer relações entre estas variáveis no grupo pesquisado.

Verificou-se que os participantes consideram como mais importante em suas vidas profissionais a "Estabilidade", a "Realização" e as "Relações Sociais". A importância dada ao fator Estabilidade foi maior do que a importância dada ao fator Realização e a importância dada ao fator Relações Sociais foi maior que a importância dada ao fator Prestígio.

No entanto, a pouca oposição entre os fatores Realização e Estabilidade pode indicar conflitos entre o que os funcionários pretendem atingir na vida e no trabalho. Esta assertiva está em consonância com as proposições de Tamayo e Paschoal (2003) de que a estrutura motivacional de cada pessoa é volátil e nem sempre harmoniosa, podendo levar a conflitos internos de acordo a concepção de oposição entre tipos motivacionais.

Esta possibilidade de conflitos internos parece mais real através da retomada ao conceito de Realização como "busca de prazer e realização pessoal e profissional, bem como de independência de pensamento e ação no trabalho por meio da autonomia intelectual e da criatividade" e de Relações Sociais como "busca de relações sociais positivas no trabalho e de contribuição positiva para a sociedade por meio do trabalho" (Porto e Tamayo, 2003, p. 151).

Sob a concepção normativa de comprometimento baseada em achar certo e moral fazê-lo, o grupo foi considerado descomprometido. É imprescindível retomar o caráter cultural que cerca este comportamento. Conforme citado anteriormente, comprometimento normativo implica congruência entre valores (O' REILLY, CHATMAN e CALDWELL, 1991, apud BASTOS, BRANDÃO e PINHO, 1997) e aceitação dos objetivos e valores (MAYER e SCHOORMAN, 1992, apud BASTOS, BRANDÃO e PINHO, 1997). O baixo escore de comprometimento normativo 
verificado (2,70 em uma escala de 1 a 5) indica divergência entre valores relativos ao trabalho e os valores declarados pela organização, além de pouca aceitação dos objetivos da organização pelos funcionários.

O maior número de funcionários considerados descomprometidos entre os que indicaram os fatores Estabilidade, Realização e Relações Sociais como importante, muito importante ou extremamente importante reforçam a possibilidade de divergência entre os valores relativos ao trabalho para o grupo pesquisado e os valores declarados pela organização.

O presente estudo poderia ser realizado em outras agências bancárias para confirmar se estas relações se repetem em outras equipes. Inclusive, seria importante verificar o perfil de valores relativos ao trabalho em participantes com escores mais altos de comprometimento normativo.

Os resultados apresentados podem subsidiar os gestores a promoverem ações para aumentar o comprometimento normativo da equipe. Isto poderia ser feito através de ações de valorização ou reconhecimento dos funcionários, considerando os valores considerados como mais importantes. Estes esforços seriam mais eficientes do que estratégias formuladas com base em princípios gerais e abstratos, como defendem Tamayo e Paschoal (2003).

É importante lembrar que o baixo comprometimento pode prejudicar o sucesso das transformações econômicas, tecnológicas e culturais pelas quais passam as instituições do mundo contemporâneo (BORGES-ANDRADE, 2002). 


\section{REFERÊNCIAS}

BASTOS, A. V. B. Comprometimento organizacional: Um balanço dos resultados e desafios que cercam essa tradição de pesquisa. Revista de Administração de Empresas. São Paulo, v. 33, n. 3, pag. 52-64, mai./jun. 1993.

BASTOS, A. V. B. Padrões de comprometimento com a Profissão e a Organização: o impacto de fatores pessoais e da natureza do trabalho. Revista de

Administração. São Paulo, v. 35, n. 4, pag. 48-60, out./dez. 2000.

BASTOS, A. V. B.; BRANDÃO, M. G. A.; PINHO, A. P. M. Comprometimento organizacional: uma análise do conceito expresso por servidores universitários do cotidiano de trabalho. Revista de Administração Contemporânea. v. 1, n. 2, pag. 97-120; mai./ago. 1997;

BASTOS, A. V. B. BORGES-ANDRADE, J. E. Comprometimento com o trabalho: padrões em diferentes contextos organizacionais. Revista de Administração de Empresas. V. 42, n. 2, pag. 31-41, abr./jun. 2002.

KRAMER, G. G.; FARIA, J. H. Vínculos Organizacionais. Revista de Administração Pública. Rio de Janeiro, v. 41, n.1, pag. 83-104, fev. 2007.

MEDEIROS, C. A. F.; ENDERS, W. T. Validação do Modelo de Conceitualização de Três Componentes do Comprometimento Organizacional (Meyer e Allen, 1991). Revista de Administração Contemporânea. V. 2, n. 3, pag. 67-87, dez. 1998.

MORIN, E.; TONELLI. M. J.; PLIOPAS, A. L. V. O trabalho e seus sentidos. Psicologia \& Sociedade, Porto Alegre, v. 19, pag. 47-56, 2007. Edição Especial 1.

PEREIRA, J.M. Metodologia Científica: Manual de Metodologia Científica. Brasília: Centro de Educação à Distância - CEAD/UnB, 2006.

PORTO, J. P.; TAMAYO, A. Escala de Valores Relativos ao Trabalho. Psicologia: Teoria e Pesquisa. Brasília, v. 19, n. 2, pág. 145-152, ago. 2003.

SCHEIN, E. H. Psicologia Organizacional: Rio de Janeiro, Prentice-Hall do Brasil, 1982.

TAMAYO, A. Valores organizacionais: sua relação com satisfação no trabalho, cidadania organizacional e comprometimento afetivo. Revista de Administração. São Paulo, v. 33, n.3, pag. 56-63, set.1998.

TAMAYO, A; PASCHOAL, T. A relação da motivação para o trabalho com as metas do trabalhador. Revista de Administração Contemporânea, Curitiba, v. 7, n. 4, pag. 33-54, dez. 2003. 
WAGNER III, J. A.; HOLLENBECK. Comportamento Organizacional, Criando Vantagem Competitiva: São Paulo, Saraiva, 1999.

ZANELLI, J. C.; BORGES-ANDRADE, J. E.; BASTOS, A. V. B. Psicologia, Organizações e Trabalho no Brasil. Porto Alegre: Artmed, 2004. 


\section{ANEXOS}

\section{Anexo A - Carta de Apresentação}

Prezado funcionário/servidor,

Esta é uma pesquisa da Universidade de Brasília sobre valores do trabalho. Para viabilizá-la procuramos a sua organização para realizar esse levantamento. Os funcionários da sua unidade foram solicitados a participar desta pesquisa tendo em vista tratar-se de uma das agências com mais funcionários na sua região. Estamos nos dirigindo a você para solicitar a sua colaboração respondendo ao questionário em anexo. Sua colaboração é fundamental para o sucesso deste trabalho.

O objetivo deste trabalho é analisar como você se relaciona com seu trabalho. A sua participação é voluntária. Se você decidir participar ou não, isto não afetará a sua relação atual ou futura com a equipe de pesquisa ou com a sua instituição. Queremos que você se sinta inteiramente à vontade para dar suas opiniões. Se você aceitar participar, pedimos que você responda um questionário que terá duração de aproximadamente $15 \mathrm{~min}$. Os participantes não serão identificados e os dados fornecidos serão utilizados apenas para fins de pesquisa. Não escreva seu nome em qualquer lugar do questionário.

Para que não haja influência nas respostas de outros funcionários que talvez estejam respondendo ao mesmo questionário, solicitamos também que você não comente suas respostas com colegas de trabalho. em branco.

Por favor, responda conforme as instruções e não deixe nenhuma questão

Qualquer dúvida entre em contato com Maria do Carmo via e-mail mclv.maria@gmail.com ou pelo telefone 8422-2970.

Agradecemos desde já a sua colaboração!

Atenciosamente, 
Marque com x a opção para as questões abaixo:

\section{1) Sexo}

( ) feminino ( ) masculino

2) Idade (em anos)

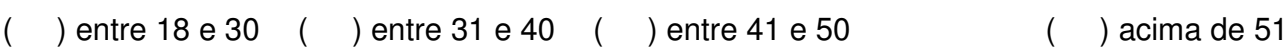

3) Escolaridade

( ) médio ( ) superior incompleto ( ) nível superior completo ( ) pós-graduação

\section{4) Estado civil}

( ) solteiro ( ) casado / união estável ( ) viúvo $\quad(\quad)$ separado / divorciado

\section{5) Número de filhos}

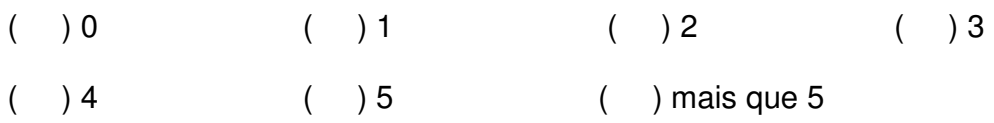

6) Religião

$\begin{array}{lll}(\quad) \text { católico } & (\text { ) evangélico } & (\text { ) budista }\end{array}$

7) Função

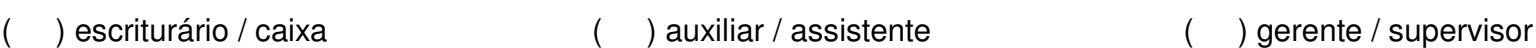

8) Tempo de serviço na empresa (em anos)

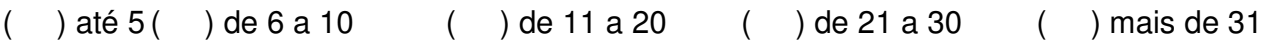

9) Salário bruto atual
( ) até $\mathrm{R} \$ 1.530,00$
( ) de $R \$ 1.530,01$, a $R \$ 3.060,00$
( ) de $\mathrm{R} \$ 3.060,01$ a $\mathrm{R} \$ 4.590,00$
( ) de $\mathrm{R} \$ 4.590,01$ a $\mathrm{R} \$ 6.120,00$
( ) de $\mathrm{R} \$ 6.120,01$ a $\mathrm{R} \$ 7.650,00$
（） acima de $R \$ 7.650,01$ 


\section{Anexo B - Escala de Valores Relativos ao Trabalho}

Neste questionário você deve perguntar a si próprio: "Quais são os motivos que me levam a trabalhar?", mesmo que, atualmente, você não esteja trabalhando. Esses motivos constituem os valores do trabalho.

A seguir, há uma lista de valores do trabalho. Pedimos sua colaboração para avaliar quão importante cada valor é para você como um princípio orientador em sua vida no trabalho, circulando o número, à direita de cada valor, que melhor indique a sua opinião. Use a escala de avaliação abaixo:

\section{COMO PRINCÍPIO ORIENTADOR EM MINHA VIDA NO TRABALHO,} esse motivo é:

\begin{tabular}{c|c|c|c|c}
\hline 1 & 2 & 3 & 4 & 5 \\
\hline $\begin{array}{c}\text { Nada } \\
\text { importante }\end{array}$ & $\begin{array}{c}\text { Pouco } \\
\text { importante }\end{array}$ & Importante & $\begin{array}{c}\text { Muito } \\
\text { importante }\end{array}$ & $\begin{array}{c}\text { Extremamente } \\
\text { importante }\end{array}$ \\
\hline
\end{tabular}

Quanto maior o número $(1,2,3,4,5)$, mais importante é o valor como um princípio orientador em sua vida no trabalho. Tente diferenciar, tanto quanto possível, os valores entre si, usando para isso todos os números. Evidentemente, você poderá repetir os números em suas respostas/avaliações.

\begin{tabular}{|c|c|c|c|c|}
\hline É importante para mim: & & & & \\
\hline 1. Estabilidade financeira & 12 & $2 \mid 3$ & & 5 \\
\hline 2. Ser independente financeiramente & 12 2 2 & $2 \mid 3$ & & 5 \\
\hline 3. Combater injustiças sociais & 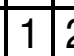 & $2 \mid 3$ & 4 & 5 \\
\hline 4. Realização profissional & 12 & $2 \sqrt[3]{2}$ & & 5 \\
\hline 5. Realizar um trabalho significativo para mim & 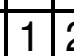 & 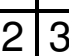 & 4 & 5 \\
\hline 6. Competitividade & 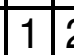 & $2 \mid 3$ & & 5 \\
\hline 7. Trabalho intelectualmente estimulante & 12 & $2 \mid 3$ & & 5 \\
\hline 8. Autonomia para estabelecer a forma de realização do trabalho & 12 & \begin{tabular}{l|l}
2 & 3
\end{tabular} & & 5 \\
\hline 9. Poder me sustentar & 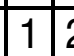 & & & 5 \\
\hline 10. Ter prazer no que faço & & 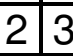 & & 5 \\
\hline 11.Conhecer pessoas & 12 & $2 \sqrt{3}$ & & 5 \\
\hline 12.Satisfação pessoal & & & & 5 \\
\hline
\end{tabular}


É importante para mim:

13. Trabalho interessante

14. Crescimento intelectual

15. Seguir a profissão da família

16. Gostar do que faço

17. Status no trabalho

18. Ganhar dinheiro

19.Ser útil para a sociedade

20. Auxiliar os colegas de trabalho

21.Preservar minha saúde

22. Ter prestígio

23. Bom relacionamento com colegas de trabalho

24. Identificar-me com o trabalho

25. Supervisionar outras pessoas

26. Amizade com colegas de trabalho

27. Competir com colegas de trabalho para alcançar as minhas metas profissionais

28. Ter compromisso social

29. Colaborar para o desenvolvimento da sociedade

30. Realização pessoal

31. Ter superioridade baseada no êxito do meu trabalho

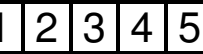

\begin{tabular}{llllll}
1 & 2 & 3 & 4 & 5 \\
\hline
\end{tabular}

32. Mudar o mundo

33.Ter fama

34. Ter notoriedade

35. Estabilidade no trabalho

36. Ajudar os outros

37.Suprir necessidades materiais

38. Enfrentar desafios

39. Ser feliz com o trabalho que realizo

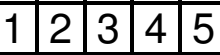

40. Trabalho variado

41. Aprimorar conhecimentos da minha profissão

42. Obter posição de destaque

43. Ter melhores condições de vida

44. Trabalho que requer originalidade e criatividade

45. Colaborar com colegas de trabalho para alcançar as metas de trabalho do grupo. 


\section{Anexo C - Modelo de Três Componentes do Comprometimento Origanizacional}

Qual imagem você tem da empresa na qual você trabalha?

Para responder a esta pergunta, marque o número que melhor corresponde à sua opinião em cada uma das afirmações a seguir, utilizando o seguinte quadro:

\begin{tabular}{c|c|c|c|c}
\hline 1 & 2 & 3 & 4 & 5 \\
\hline $\begin{array}{c}\text { Discordo } \\
\text { totalmente }\end{array}$ & $\begin{array}{c}\text { Discordo } \\
\text { parcialmente }\end{array}$ & $\begin{array}{c}\text { Nem concordo } \\
\text { nem discordo }\end{array}$ & $\begin{array}{c}\text { Concordo } \\
\text { parcialmente }\end{array}$ & $\begin{array}{c}\text { Concordo } \\
\text { totalmente }\end{array}$ \\
\hline
\end{tabular}

\begin{tabular}{|c|c|c|c|c|c|}
\hline $\begin{array}{l}01 \text { - Eu seria muito feliz em dedicar o resto da minha carreira nesta } \\
\text { organização. }\end{array}$ & 1 & 2 & 3 & 4 & 5 \\
\hline 02 - Eu realmente sinto os problemas da organização como se fossem meus. & 1 & 2 & 3 & 4 & 5 \\
\hline 03 - Eu não sinto um forte senso de integração com esta organização. & 1 & 2 & 3 & 4 & 5 \\
\hline 04 - Eu não me sinto emocionalmente vinculado a esta organização & 1 & 2 & 3 & 4 & 5 \\
\hline 05 - Eu não me sinto como uma pessoa de casa nesta organização. & 1 & 2 & 3 & 4 & 5 \\
\hline 06 - Esta organização tem um imenso significado pessoal para mim. & 1 & 2 & 3 & 4 & 5 \\
\hline $\begin{array}{l}07 \text { - Na situação atual, ficar nesta organização é na realidade uma } \\
\text { necessidade mais do que um desejo. }\end{array}$ & 1 & 2 & 3 & 4 & 5 \\
\hline $\begin{array}{l}08 \text { - Mesmo que eu quisesse, seria muito difícil para mim deixar esta } \\
\text { organização agora. }\end{array}$ & 1 & 2 & 3 & 4 & 5 \\
\hline $\begin{array}{l}09 \text { - Se eu decidisse deixar essa organização agora, minha vida ficaria } \\
\text { bastante desestruturada. }\end{array}$ & 1 & 2 & 3 & 4 & 5 \\
\hline 10 - Eu acho que teria poucas alternativas se deixasse essa organização. & 1 & 2 & 3 & 4 & 5 \\
\hline $\begin{array}{l}11 \text { - Se eu já não tivesse dado tanto de mim nesta organização, eu poderia } \\
\text { pensar em trabalhar num outro lugar. }\end{array}$ & 1 & 2 & 3 & 4 & 5 \\
\hline $\begin{array}{l}12 \text { - Uma das poucas conseqüências negativas de deixar essa organização } \\
\text { seria a escassez de alternativas imediatas. }\end{array}$ & 1 & 2 & 3 & 4 & 5 \\
\hline 13 - Eu não sinto nenhuma obrigação de permanecer nesta organização. & 1 & 2 & 3 & 4 & 5 \\
\hline $\begin{array}{l}14 \text { - Mesmo se fosse vantagem para mim, sinto que não seria certo deixar } \\
\text { essa organização agora. }\end{array}$ & 1 & 2 & 3 & 4 & 5 \\
\hline 15 - Eu me sentiria culpado se deixasse essa organização agora. & 1 & 2 & 3 & 4 & 5 \\
\hline 16 - Essa organização merece minha lealdade. & 1 & 2 & 3 & 4 & 5 \\
\hline $\begin{array}{l}17 \text { Eu não deixaria essa organização agora porque tenho uma obrigação moral } \\
\text { com as pessoas daqui. }\end{array}$ & 1 & 2 & 3 & 4 & 5 \\
\hline 18 - Eu devo muito a essa organização & 1 & 2 & 3 & 4 & 5 \\
\hline
\end{tabular}

